\title{
ERRATUM
}

Med \& Health 2018 Jun 13(1); 3-11. doi: 10.17576/MH.2018.1301.02

\section{Role of Translaminar Pressure Gradient Differences in Glaucoma - A Review}

\author{
MUHAMMAD SYAMIL MS, JEMAIMA CH
}

Department of Ophthalmology, Universiti Kebangsaan Malaysia Medical Centre, Jalan Yaacob Latif, Bandar Tun Razak, 56000 Cheras, Kuala Lumpur, Malaysia.

According to the request by the author, the affiliation is corrected to:

$$
\text { MUHAMMAD SYAMIL MS }{ }^{1,2} \text {, JEMAIMA CH}{ }^{1}
$$

'Department of Ophthalmology, Universiti Kebangsaan Malaysia Medical Centre, Jalan Yaacob Latif, Bandar Tun Razak, 56000 Cheras, Kuala Lumpur, Malaysia.

${ }^{2}$ Ophthalmology Unit, Department of Surgery, Medical and Health Science Faculty, Universiti Putra Malaysia, 43000 Serdang, Selangor, Malaysia 